\title{
EDUCAÇÃO TUTORIAL COMO FERRAMENTA NO ENSINO-APRENDIZAGEM AUDIOVISUAL
}


EDUCAÇÃO TUTORIAL COMO FERRAMENTA NO ENSINO-APRENDIZAGEM AUDIOVISUAL

Resumo: O presente trabalho objetiva destacar a importância de um Programa de Educação Tutorial (PET) para os cursos de graduação, em articulação com os programas de pós-graduação, destacando a relevância da tríade ensino, pesquisa e extensão também presentes no PET Interdisciplinar em Rádio e Televisão da FAAC/UNESP.

Palavras chave: Comunicação Audiovisual; Educação Tutorial; Rádio e Televisão

EDUCACIÓN TUTORIAL COMO HERRAMIENTA DE ENSEÑANZA-APRENDIZAJE AUDIOVISUAL

Resumo: Este trabajo tiene como objetivo destacar la importancia del Programa de Educación Tutorial (PET) para cursos de pregrado en conjunto con los programas de postgrado, destacando la importancia de la triade enseñanza, investigación y extensión también presentes en el PET Interdisciplinario en Radio y Televisión FAAC/ UNESP.

Palabras clave: Comunicación Audiovisual; Educación Tutorial; Radio y Televisión

TUTORIAL EDUCATION AS TOOL OF AUDIOVISUAL TEACHING-LEARNING

Abstract: This paper aims to highlight the importance of Tutorial Education Program (TEP) for undergraduate courses in conjunction with the graduate programs, highlighting the relevance of the triad teaching, research and extension activities also present in the TEP Interdisciplinary in Radio and Television from the FAAC/UNESP.

Key words: Audiovisual Communication; Tutorial Education; Radio And Television 


\section{INTRODUÇÃO}

Os cursos de Comunicação Social e Design da Faculdade de Arquitetura, Artes e Comunicação (FAAC), do câmpus de Bauru da Unesp, não podem ficar alijados do intenso movimento social, econômico e cultural desencadeado pela denominada "Era da Informação e do Conhecimento". Um dos desafios imediatos dos sistemas públicos de ensino superior é manter professores-pesquisadores atentos para as interferências sistêmicas provocadas pelos atuais meios digitais de comunicação, com seus fluxos de informações multilaterais e interfaces convergentes e interativas. Tais veículos e dispositivos digitais se transformam simultaneamente em ferramentas e em ambientes individuais e coletivos, de trabalho e de produção material e simbólica, e também em espaços públicos virtuais de sociabilidade e de formação cultural, onde prosperam possibilidades comunicativas como o ativismo político, artístico, religioso, comportamental, comercial e publicitário, entre outras manifestações sociais.

Os efeitos individuais e sociais derivados da infinidade de conteúdos difundidos pelos novos veículos e serviços de informação sobre a existência cotidiana das diversas camadas da população brasileira exigem conhecimento atual e contextualizado. Isso é possível de se obter com ensino multidisciplinar e pesquisa complexa, que mobilize profissionais de Comunicação e Design, cientistas sociais e comportamentais, pesquisadores de mídia e de tendências do mercado de trabalho. Só com equipes e estudos complexos e multidisciplinares será possível entender os modos contemporâneos de uso e de interação que crianças, adolescentes, jovens e também as faixas etárias mais velhas estabelecem com o computador, com a internet, com os videogames e celulares. Obviamente, que as pesquisas não poderão desconsiderar veículos tradicionais e abrangentes como o cinema, o rádio e a televisão, que começam a ser transformados pelos recursos da digitalização, pela interatividade e a convergência audiovisual.

Na FAAC-Unesp, o desafio para ensinar e pesquisar sobre assuntos tão abrangentes e complexos esbarra na escassez recursos orçamentários, de laboratórios e principalmente de pessoal técnico-administrativo e docente para sustentar com fôlego a estrutura didático-pedagógica para formação profissional e científica dos cursos de graduação e também de pós-graduação. As dificuldades que afligem os quadros docentes dos cursos de Comunicação e Design se agravam com a aceleração dos processos de inovação científica e tecnológica determinada pela profusão de plataformas e dispositivos digitais 
que se popularizam entre os brasileiros das diversas camadas sociais.

Para manter a atualidade e a adequação dos projetos políticos pedagógicos dos cursos seria necessário realizar sucessivas reformas curriculares, uma medida pouco viável pelo tempo e energia coletiva que despenderia. Além disso, em função da necessidade de reclivagem do campo e natureza social da televisão e da comunicação audiovisual no âmbito da formação em graduação e pós-graduação, destaca-se a necessidade de adoção de conceitos, métodos e instrumentos de investigação e de ensino-aprendizagem contemporâneos para a formação profissional. É preciso dar ênfase à pesquisa e formação especializada em rádio, televisão, audiovisual e design já entendidos como meios digitais e em processos de comunicação convergente e interativa. São novas exigências de formação válidas para profissionais que irão atuar em veículos midiáticos comerciais, ou em novos sistemas coletivos e colaborativos de comunicação, que prosperam nas redes sociais do ciberespaço, sem vínculos absolutos com as regras e finalidades da antiga indústria cultural.

Os atuais profissionais com formação em áreas da Comunicação e Design atuam no mercado de rádio, de televisão, de cinema, de publicidade e propaganda, de design industrial e gráfico, em Internet, em diversas atividades de jornalismo, entretenimento, educação e cultura. Muitos também exercem várias funções e habilidades em setores e atividades comerciais e sociais, que utilizam conhecimentos e produtos de comunicação audiovisual e de distintos conhecimentos de design e também de artes. As possibilidades de atuação satisfatória dos formados em cursos de comunicação e de design em meios e sistemas digitais de comunicação, que estão em permanente transformação técnica, conceitual, estética e profissional, também dependem de uma formação universitária atualizada, abrangente, versátil e crítica, que lhes permita desempenhar vários papéis e funções, muitas vezes, de forma concomitante.

Cursos adequados não devem prescindir de novos conhecimentos, de valores sociopolíticos e éticos, de instrumentos, suportes, processos e projetos para pesquisa, ensino, produção e veiculação de conteúdos e linguagens informativas, sejam artísticas, jornalísticas, culturais ou educativas. Nas áreas de Comunicação e de Design da FAAC, os recursos e as iniciativas derivadas de projetos de pesquisa e de extensão permitiram para os cursos de graduação, criar ao longo do tempo algumas estruturas digitais minimamente compatíveis com as novas exigências de formação profissional, com as novas funções laborais, com a investigação e desenvolvimento de produtos para comunicação e 
para atender as demandas sociais.

No entanto, é preciso buscar mais recursos, insumos e articulação para intensificar a sinergia interdisciplinar nas ações de ensino-aprendizagem entre os cursos de graduação, e também com os três programas de pós-graduação da Faculdade. Afinal, grande parte da formação dos estudantes também ocorre em atividades e projetos extracurriculares, que propiciam a realização de eventos acadêmicos, de estudos teóricos e de experimentação profissional. De imediato, a medida prática concebida para iniciar um movimento permanente de estudo e reflexão sobre o estado da arte dos cursos de Comunicação e Design da FAAC foi desenvolver um Projeto de Educação Tutorial (PET) Interdisciplinar em Rádio e Televisão para a FAAC.

\section{A ORIGEM E AS FINALIDADES DO PROGRAMA DE EDUCAÇÃO TU- TORIAL (PET)}

O Programa de Educação Tutorial (PET) foi criado em 1979 pela Coordenação de Aperfeiçoamento de Pessoal de Nível Superior (CAPES), com a denominação de 'Programa Especial de Treinamento'. Sob a orientação de um tutor, o projeto tinha por principais finalidades, propiciar aos estudantes possibilidades de complemento da formação acadêmica e dar condições para se criar iniciativas para a melhoria dos cursos de Graduação em articulação com os Programas de Pós-graduação. O objetivo central era atender "as necessidades do país, nas diversas áreas do conhecimento científico e tecnológico". (DESSEN,1995).

O Programa era destinado aos grupos de alunos que demonstrassem potencial, habilidades e grande interesse nos cursos de graduação da Instituição de Ensino (IES) em que estudavam.

O Programa Especial de Treinamento constitui-se, portanto, em uma modalidade de investimento acadêmico em cursos de graduação que têm sérios compromissos epistemológicos, pedagógicos, éticos e sociais. Com uma concepção baseada nos moldes de grupos tutoriais de aprendizagem e orientado pelo objetivo de formar globalmente o aluno, o PET não visa apenas proporcionar aos bolsistas e aos alunos do curso uma gama nova e diversificada de conhecimento acadêmico, mas assume a responsabilidade de contribuir para sua melhor qualificação como pessoa humana e como membro da sociedade. (Manual de Orientações Básicas, 2006) 
O Programa foi gerenciado pela CAPES até o final do ano de 1999 e teve a gestão assumida pelo Departamento de Modernização e Programas da Educação Superior (DEPEM) da Secretaria de Educação Superior do Ministério da Educação, SESU/MEC. Durante o VIII Encontro Nacional dos Grupos PET (ENAPET), realizado na Universidade Federal de Pernambuco em 2002, o Programa Especial de Treinamento foi renomeado pelo então Ministro da Educação, Cristovam Buarque, passando a ter a atual denominação.

O PET foi se desenvolvendo ao longo dos anos, com avanços e retrocessos qualitativos e quantitativos. Inclusive as diversas ameaças de extinção do Programa possibilitaram uma maior mobilização entre os grupos e IES envolvidas. Em 2002, foi aprovado um novo Manual de Orientações Básicas do PET e em 2005 o MEC publicou as portarias 647/2002 e 648/2002, que estabeleceram as diretrizes do Programa e a constituição da Comissão Nacional de Acompanhamento e Avaliação do PET. As novas medidas permitiram a retomada da avaliação nacional e o reconhecimento da qualidade do Programa. Além disso, foi aprovado no âmbito da Câmara dos deputados, o projeto de Lei 4628/2001, que cria amparo legal para o PET. Gradativamente, houve o reconhecimento da importância do PET como instrumento de aperfeiçoamento do ensino superior no Brasil. De acordo com o Portal do MEC, "o Programa de Educação Tutorial conta em todo país, com 400 grupos em instituições públicas e privadas de ensino superior. São 4.274 alunos bolsistas e 400 tutores, um para cada grupo de pesquisa".

Em síntese, o Programa funciona com um método tutorial em que o tutor é o responsável por estimular e auxiliar a aprendizagem ativa dos integrantes do Grupo por meio de vivências, reflexões e discussões. O método adotado busca fugir do ambiente vivenciado em salas de aula, na maioria das vezes passivo com a figura do professor designado como transmissor do conhecimento e o estudante como elemento de assimilação.

No método tutorial do PET objetiva-se a construção de espaços de novos saberes e o desenvolvimento de processos e métodos gerais e específicos de investigação necessários para tal produção. Nesse ínterim, o tutor exerce a função e estimulador da aprendizagem ativa dos alunos "através de vivências, reflexões e discussões, num clima de informalidade e cooperação" (DESSEN, 1995). O estudante petiano é considerado um agente multiplicador e disseminador de ideias entre os estudantes do curso em uma perspectiva de construção coletiva do conhecimento, incluindo nesse processo o desenvolvimento do projeto pedagógico do(s) curso(s) envolvido(s). 
Nesse ponto, o PET se diferencia, por exemplo, dos programas de Iniciação Científica, que trabalham apenas com pesquisa, e dos Projetos de Extensão Universitária. As atividades de ensino estão relacionadas ao aprofundamento conceitual de determinados conhecimentos por meio de grupos de estudos, organização de palestras, de aulas ministradas pelos próprios alunos dentro ou fora da Universidade. Isso possibilita o desenvolvimento de novas práticas e experiências pedagógicas no âmbito do curso, permitindo uma formação diversificada, e um contato com a sociedade, quebrando o isolamento do conhecimento científico.

A pesquisa estabelece uma conexão com o ensino e não está necessariamente relacionada a demandas sociais, podendo se configurar como um "saber desinteressado". Além disso, há a possibilidade de realização de pesquisas que contemplem áreas diferentes, promovendo uma ligação entre as áreas e diminuindo a fragmentação do conhecimento, isso pelo fato dos grupos PET não se restringirem a uma determinada área de conhecimento. As atividades de extensão possibilitam a transformação social a partir do conhecimento e a produção de conhecimento por meio da prática, além de possibilitar com que os alunos exercitem a cidadania e reflexão sobre questões relevantes à sociedade. Logo, o petiano adquire caráter crítico e atuante, contribuindo para a comunidade científica com as suas pesquisas, colaborando com a sociedade por suas atividades de extensão e desenvolvendo o conhecimento acadêmico através do ensino, dimensões separadas somente por motivos didáticos.

O Programa de Educação Tutorial, em síntese, objetiva integrar os petianos bolsistas com os quadros docente e discente da instituição, inclusive em nível de pós-graduação; estimular a consciência do papel do aluno frente à sociedade; desenvolver ações coletivas e a capacidade de trabalhar em grupo; envolver os alunos em tarefas e atividades que propiciem o aprender fazendo e refletindo sobre; discutir temas éticos, sócio-políticos, científicos e culturais relevantes para o país ou para o exercício profissional e para a construção da cidadania.

Atualmente há três tipos de Grupo PET MEC/SESU: PET convencional, dividido em PET Curso e PET interdisciplinar, e PET Conexões de Saberes. O modelo PET Convencional é o mais antigo formado por grupos associados a cursos de graduação, podendo ser um específico (PET Curso) ou com escopo interdisciplinar (PET Interdisciplinar). O PET conexões de saberes foi criado em 2006 e tem caráter intervencionista, com foco no trabalho com comunidades populares urbanas, campo, quilombola ou indígenas. São voltados à diversidade 
social, constituído por bolsistas em condição de vulnerabilidade social e econômica. O PET Conexões de Saberes não é assistencialista, à medida que o que o diferencia do modelo de PET convencional é somente o publico alvo.

\section{A IMPORTÂNCIA DOS PROJETOS PET NA UNESP E A EXPERIÊNCIA INICIAL DO PET-RTV}

A Unesp é a IES brasileira com maior número de grupos do Programa de Educação Tutorial - PET MEC/SESU. Em 2011, eram 30 grupos em 16 Unidades Universitárias, distribuídas em 10 câmpus. Apenas duas unidades não possuem cursos com vínculo a algum Programa de Educação Tutorial: - a Faculdade de Medicina, em Botucatu, e a Faculdade de Medicina Veterinária de Araçatuba. Além dos grupos ligados ao Ministério da Educação, a Unesp mantém 15 novos projetos PET institucionais, com recursos repassados pela Pró-Reitoria de Graduação (Prograd), o que totaliza 45 grupos distribuídos conforme o gráfico a seguir:

\section{Gráfico 01 PET na Unesp}

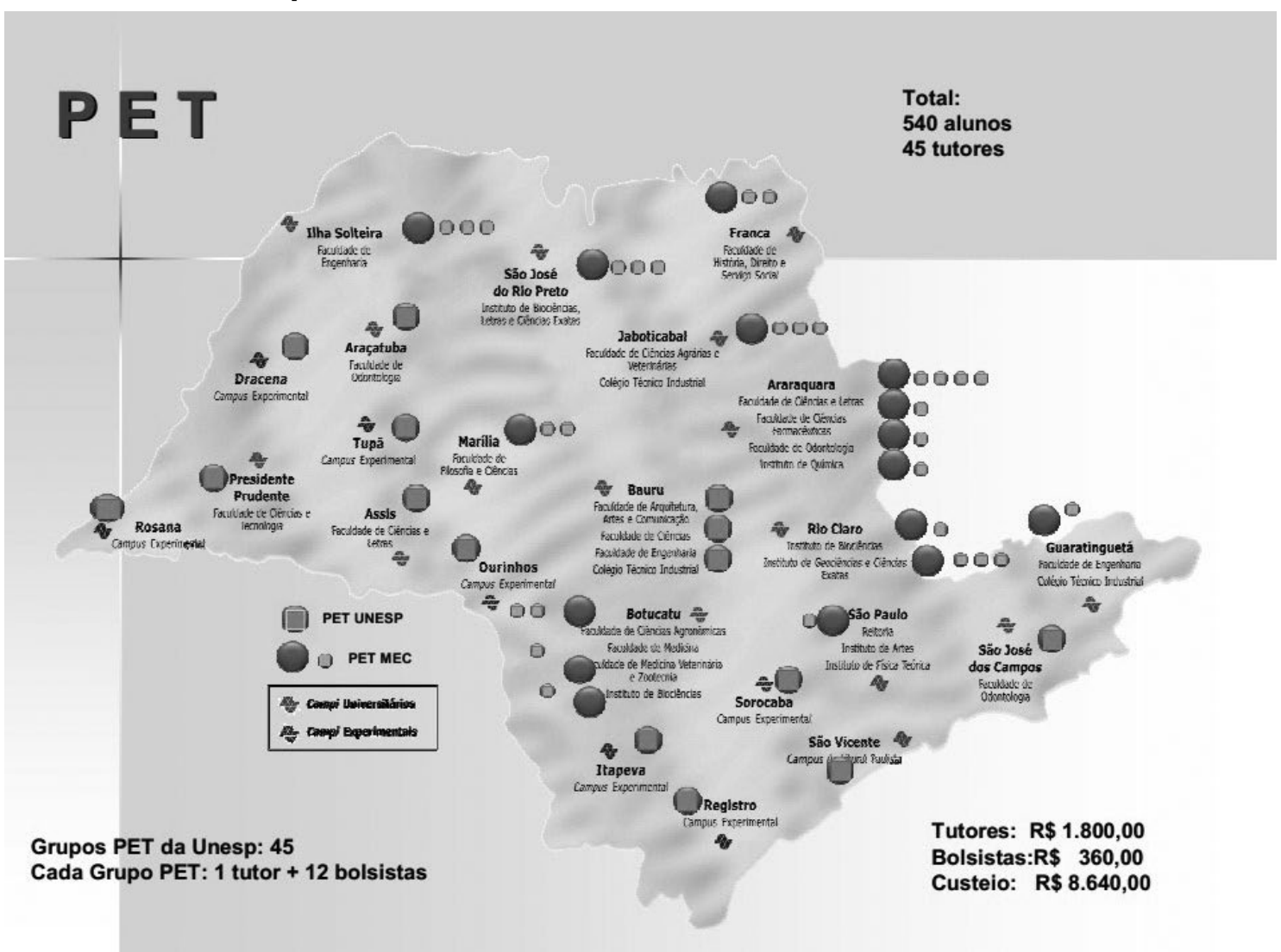

Fonte: Portal Prograd Unesp, disponível em <http://unesp.br/prograd//mostra_arq_multi. php?arquivo $=9257>$ Acesso em 20 de setembro de 2012 
Somente em 2011, foram implantados 12 novos Grupos Institucionais, entre eles o Grupo de Rádio e Televisão (PET-RTV). A existência de um Grupo PET Interdisciplinar na FAAC/Unesp fortaleceu o objetivo comum de professores e de estudantes de viabilizar o desenvolvimento de projetos político/pedagógicos capazes de realizar formação universitária compatível com todas as demandas sociais e de promover atividades extracurriculares e interdisciplinares.

\section{PET INTERDISCIPLINAR EM RÁdIO E TELEVISÃO DA FAAC: UM INSTRUMENTO COLETIVO PARA ATUALIZAR OS CURSOS DE CO- MUNICAÇÃO E DESIGN}

O Projeto PET Interdisciplinar de Rádio e Televisão (RTV) está em funcionamento desde junho de 2011 após ter sido aprovado pelo Comitê Local de Acompanhamento - CLA em seleção institucional definida pela PROGRAD-Unesp no edital 01/2011, de acordo com os critérios estabelecidos pelo MEC/SESU. O Projeto PET-RTV vem desenvolvendo nos cursos de Radialismo, Jornalismo, Relações Públicas e Design, da FAAC do câmpus de Bauru da Unesp, ações extracurriculares de ensino, pesquisa e extensão, para induzir mudanças e melhorias nos cursos de graduação abrangidos pela área interdisciplinar.

O Projeto foi articulado para propiciar um ambiente interdisciplinar de aprendizado, de profissionalização, extensão e pesquisa, para a comunidade interna e externa. As atividades realizadas têm servido para a avaliação e a atualização dos cursos, ações que poderão amenizar a evasão e a retenção de estudantes nas diversas áreas de formação inseridas no campo de ação do PET-RTV/FAAC-Unesp. A equipe interdisciplinar de 12 petianos bolsistas e 6 voluntários tem conseguido manter ao longo de 15 meses de funcionamento, um proveitoso intercâmbio acadêmico com os estudantes dos Programas de Pósgraduação em: 1) Televisão Digital: Informação e Conhecimento, 2) em Comunicação e 3) em Design da FAAC/Unesp.

A proposta do Grupo PET Interdisciplinar de Rádio e Televisão surgiu da necessidade objetiva de agregar diversos campos dessa grande área, em que a comunicação audiovisual-midiática está transversalmente presente para todos, com concepções teóricas, criativas e produtivas cada vez mais sincréticas, e com processos e tecnologias de difusão e de fruição sempre mais convergentes. O desenvolvimento do projeto está permitindo adicionar novos conhecimentos sobre fundamentos e práticas de ensino em áreas conceituais e aplica- 
das e tem servido como fórum de discussão sobre a avaliação e a atualização dos projetos político-pedagógicos dos cursos, ações que, em curto e médio prazo, poderão amenizar a evasão e retenção das diversas áreas de formação inseridas no campo de ação do PET-RTV/FAAC-Unesp.

Dessa forma, o projeto PET tem priorizado realizar diversas ações e eventos estreitamente vinculados aos objetivos específicos de formação para a Comunicação e Produção Audiovisual contidos nos Projeto Pedagógicos dos Cursos de Radialismo, Jornalismo, Relações Públicas e Design. O objetivo dessa área de Comunicação é formar profissionais com métodos, teorias e tecnologias que correspondam ativamente aos novos e antigos problemas conceituais, ético-deontológicos, sociais e também mercadológicos. Portanto, a proposta interdisciplinar do Grupo PET de Rádio e Televisão completará o campo de atividades em desenvolvimento pela área de Comunicação Social e Design da FAAC/Unesp/Bauru.

\section{A ADEQUAÇÃO DA EDUCAÇÃO TUTORIAL PARA A FORMAÇÃO EM AUDIOVISUAL}

Ao pensarmos a proposta do Projeto PET Interdisciplinar de Rádio e Televisão, consideramos em primeiro plano a necessidade de incrementar ações imediatas que ajudassem a melhorar a qualidade dos cursos de graduação em Comunicação Social e em Design, da Faculdade de Arquitetura, Artes e Comunicação (FAAC), da Unesp de Bauru. São áreas de formação superior que enfrentam imensos desafios tecnológicos, conceituais e profissionais devido ao prolongado período de transição tecnológica, mercadológica e cultural, que fustiga os atuais meios de comunicação.

Outra contribuição evidente do Grupo PET-RTV é reforçar a vocação para o ensino de qualidade da Unesp, que tem forte presença na oferta nacional de vagas públicas para a formação presencial de educadores e de outras inúmeras carreiras profissionais. Embora ensino presencial tenha raízes sólidas na tradição pedagógica da Unesp, hoje a Instituição começa a investir em desenvolvimento de polos produtores de Educação Assistida por Recursos Informáticos e Audiovisuais (EARIA) e de recursos e sistemas de Educação a Distância (EaD).

O grupo PET-RTV estabeleceu desde o mês de maio de 2011, acordo de cooperação com as direções da Rádio UNESP FM e da TV Universitária, veículos de comunicação do Centro de Rádio e Televisão Cultural Educativo da Unesp, para 
que os petianos bolsistas e voluntários possam desenvolver atividades e projetos supervisionados dedicados à pesquisa e desenvolvimento de formatos e produtos sonoros e audiovisuais. Desde o início das atividades na Rádio UNESP FM, os petianos de Rádio e Televisão puderam ter contato com os setores de Produção Radiofônica, Técnica e edição de Áudio e Discografia. Os bolsistas e voluntários do curso de Jornalismo realizam a produção do programa "Cidade Universitária", atividade coordenada pelo Núcleo de Jornalismo da Rádio Unesp FM (www.radio.unesp.br). O programa é veiculado de segunda a sexta-feira, às 7 h45 e às 18h, com duração de 15 minutos. Parte dos assuntos pautados pela equipe do"Cidade Universitária", também são utilizados para a produção de podcasts, veiculados pelo Portal PET (www.petrtv.unesp.br), reforçando a convergência de plataformas, armazenamento das notícias e rapidez de acesso aos conteúdos produzidos, além de disponibilizar materiais para a Rádio Unesp Virtual (http://www.radiovirtual.unesp.br), Projeto de Extensão da FAAC/Unesp.

O Grupo PET tem mantido vínculo regular com a equipe de profissionais e com as atividades de pesquisa e de desenvolvimento de conteúdos para programação da TV Educativa Unesp (TVU), instalada recentemente no campus de Bauru. Os petianos bolsistas do último ano de Radialismo e de Design participaram de atividades supervisionadas nos setores de Produção Audiovisual e Videografismo da TVU e vêm desenvolvendo uma série de interprogramas com 2 minutos de duração, denominado Link.

O interprograma Link propõe apresentar ao público da TV Universitária UNESP (TVU), informações atualizadas sobre o contexto digital e a sociedade da informação, a partir de produções feitas com recursos web, para mostrar o desenvolvimento da internet e de outras plataformas digitais, que se constituem definitivamente como instrumentos produtivos, de comunicação e de difusão cultural. Os novos recursos digitais inserem nas relações sociais cotidianas, a convivência e a produção material e simbólica multimidiática.

Em meio a essa discussão, a Televisão Universitária Unesp desponta como um polo institucional com estrutura técnica e profissional para pesquisa e desenvolvimento de formatos e produtos audiovisuais para ensino-aprendizado presencial e remoto. A TVU poderá ser um ambiente produtivo estratégico para que a Unesp aumente a sua participação nacional no campo de várias modalidades de Comunicação Educativa e tem servido de motivação para o Grupo PET criar produtos e objetos de ensino-aprendizagem em TVD, seguindo a demanda de atualização pedagógica dos cursos da FAAC e de outras áreas de formação da Universidade. 
Com a diversidade de áreas de conhecimento de que dispõe, a Unesp pode ampliar imensamente com o uso de recursos e sistemas virtuais e interativos de educação. A presença dos campi universitários da Unesp em todas as regiões do Estado de São Paulo favorece a criação e a expansão de tal modalidade de ensino para a formação e para a atualização profissional.

As duas Pró-Reitorias, a de Extensão (PROEX) e a de Graduação (PROGRAD), tem intensificado a formação de docentes da Unesp para o uso de recursos infocomunicativos e audiovisuais, tanto para práticas didático-pedagógicas presenciais, quanto para formação modular ou continuada a distância. $O$ projeto institucional com mobilização de mais professores da instituição são as Oficinas Pedagógicas de Formação Contínua de Docentes da Unesp. Uma de suas principais finalidades da iniciativa é a de fornecer subsídios teóricos e práticos sobre o processo de ensino e aprendizagem com o uso regular de recursos, de suportes e de redes multimidiáticas.

Outro passo decisivo da Unesp para a adoção de uma política institucional e permanente de EARIA e EaD, foi o seu ingresso no consórcio Univesp (Universidade Virtual do Estado de São Paulo). A Univesp fornece o suporte material, financeiro e tecnológico para os cursos oferecidos pelas três universidades, que assumem a tarefa de elaborar os projetos e conteúdos dos cursos e a seleção e a avaliação dos alunos. A Unesp estreou sua participação na Univesp com o curso de Licenciatura em Pedagogia, modalidade à distância, propiciando formação em nível superior para professores da Educação Básica da Rede Pública Municipal e Estadual, proporcionando formação para exercício do magistério na Educação Infantil, nas séries iniciais do Ensino Fundamental e na Gestão Escolar.

O Grupo PET-RTV, apesar de desenvolver uma extensa agenda para o atendimento das demandas internas de ensino e de pesquisa, também tem se preocupado em repassar métodos, processos e conhecimentos para toda a sociedade, em ações de extensão voltadas para a melhoria do ensino fundamental e médio. O Grupo está desenvolvendo sua atividade extensionista no Projeto "Alfabetização audiovisual educativa", que tem por finalidade o ensino -aprendizado para professores das Redes Públicas de Educação Básica, sobre de produção de vídeos e outros formatos audiovisuais educativos. O Projeto é organizado e desenvolvido pelos alunos bolsistas e voluntários do PET, por professores e alunos participantes do Grupo de Estudos em Comunicação e Educação Midiática (GECEM), do Programa de Pós Graduação em "TV Digital - Informação e Conhecimento" e também pelos professores de escolas dos 
Sistemas Públicos de Ensino, que se interessarem pela atividade. Os trabalhos são organizados em oficinas (oficinas de construção da linguagem; gêneros do audiovisual; fotografia; equipamentos: câmara, áudio, tripé, microfone; elaboração de roteiro; produção; gravação, edição, programas de edição). O objetivo é orientar professores da rede pública de ensino na produção de uma série de vídeos e de outros recursos pedagógicos audiovisuais vinculados ao objeto de formação e ao ambiente escolar dos professores-aprendizes do Projeto "Alfabetização audiovisual educativa".

A formação do Grupo PET de Rádio e Televisão está contribuindo com os processos de ensino-aprendizagem dos cursos ao focar todos os aspectos de concepção e produção audiovisual, prioritariamente em tecnologias digitais, multimidiáticas e convergentes. A Diretoria da FAAC acolheu positivamente a seleção do Grupo pela PROGRAD-Unesp e cedeu uma sala-laboratório com computadores, projetor multimídia e uma ilha de edição audiovisual (equipamentos para a produção e edição audiovisual), para que os petianos bolsistas e voluntários possam cumprir a carga horária semanal regulamentar e desenvolver as atividades e reuniões previstas no calendário mensal.

Além do apoio institucional da PROGRAD-Unesp, que sustenta o projeto com recursos institucionais para o custeio das atividades realizadas, para o pagamento de bolsas para o tutor e para os 12 alunos selecionados, há também contrapartidas da Diretoria da Faculdade de Arquitetura, Artes e Comunicação, que cedeu a sala-laboratório do PET, e também da Chefia do Departamento de Comunicação e das coordenadorias de cursos, que permitem o uso regular da estrutura dos laboratórios didáticos para desenvolver as atividades previstas.

Outro reforço conceitual e logístico para PET-RTV é derivado do LECOTEC Laboratório de Estudos Em Comunicação, Tecnologia e Educação Cidadã (http:// www2.faac.unesp.br/pesquisa/lecotec/), grupo de pesquisa ao qual o tutor é vinculado, cujo foco abrange tecnologias, linguagens e formatos de Comunicação Audiovisual Educativa para EaD, comunicação eletrônica de massa, políticas públicas de comunicação, economia política da comunicação, educação e cultura digital e comunicação e difusão científica. O LECOTEC mantém projetos de pesquisa, de extensão e de desenvolvimento de produtos de comunicação e de educação vinculados aos cursos de graduação e aos programas de pósgraduação da Faculdade de Arquitetura, Artes e Comunicação da Unesp.

$O$ aspecto multidisciplinar e multiprofissional do Projeto PET-RTV está propiciando aos petianos, voluntários e estudantes que participam das atividades 
presenciais feitas pelo grupo, ou que acessam as informações e registros audiovisuais disponibilizados nos ambientes e ferramentas de comunicação do projeto a chance de receber e repassar experiências e informações especializadas. O desenvolvimento de projetos de comunicação em veículos digitais proporciona aos participantes o conhecimento sobre a arquitetura de hardwares e softwares necessários para a captação, edição, armazenamento emissão de áudio, de texto e de imagens. São instrumentos e etapas indispensáveis para a produção de formatos, para o planejamento e gerenciamento de programação e a veiculação de produtos audiovisuais.

A articulação do PET com o ensino de graduação, e também com a pós-graduação, tem possibilitado a promoção de eventos e atividades em comum, com estudos teóricos, com a experimentação de novos formatos e de linguagens audiovisuais. São atividades integradas que viabilizam o amplo aprimoramento da habilidade técnica dos alunos bolsistas e voluntários sobre hardware e software de Rádio Digital (RD), TV Digital (TVD) e Internet, para que eles possam conceber e desenvolver produtos audiovisuais interativos ou com novas possibilidades narrativas para programas jornalísticos, de entretenimento, culturais e educativos.

Durante os 15 meses de atuação como Projeto Institucional, o Grupo PET de Rádio e Televisão tem conseguido realizar parcerias internas e externas para a realização de atividades inerentes aos objetivos diretos ou transversais previstos. Uma das parcerias externas realizadas pelo PET-RTV foi com o Grupo Enxame Coletivo, da Rede Fora do Eixo de Projetos Culturais, para a realização da Mostra Universitária de Audiovisual durante a "Virada Cultural Audiovisual" 2012.

O Enxame Coletivo é um empreendimento solidário de comunicação e cultura atuante no campo da cultura independente existente desde dezembro de 2009 e sediado em Bauru (SP). Baseia-se na lógica de trabalho colaborativo e utiliza ferramentas de internet e conceitos de economia solidária para realizar eventos, produzir conteúdos e fomentar iniciativas para criar meios e recursos para sustentar os grupos de cultura local. O grupo propôs uma parceria com o PET Rádio e TV para que fossem levados à comunidade bauruense durante a "Virada Cultural Audiovisual" 2012, os produtos realizados por universitários, tanto da Unesp, quanto de outras universidades. Para isso foram realizadas as inscrições de curtas-metragens, que deveriam comprovar seu vínculo com alguma instituição de ensino superior. Ao todo, foram exibidos seis curta-metragens incluindo várias produções feitas por petianos, em atividades de graduação.

A 'Virada Audiovisual' foi pensada para consolidar um ciclo de atividades ci- 
neclubistas realizado pelo Grupo PET. O Cine PET-RTV é uma atividade de apresentação e discussão de filmes, com o objetivo de analisar o roteiro, o cenário, os processos e técnicas de produção, o contexto histórico e outros aspectos relevantes, que estejam identificados no filme escolhido para exibição em uma determinada sessão. Os membros do grupo participam da atividade e são responsáveis pela escolha dos filmes, além de um convidado para conduzir as discussões sobre a temática pré-definida. O Cine PET realizou algumas sessões em parceria com o Cine Clube Unesp, Projeto de Extensão Universitária da FAAC/Unesp.

Devido à constante necessidade de discutir assuntos atuais e de efeitos transversais importantes para a formação universitária e de amplo interesse social, o Grupo PET-RTV criou o 'Ciclo de Debates PET', um espaço de diálogo aberto e gratuito, para participação da comunidade interna e externa. $O$ 'Ciclo de Debates PET' prioriza temáticas do universo curricular e extra-curricular, como mudanças de conhecimento, de políticas e de estruturas legais, sobre as profissões derivadas da comunicação e do campo cultural, práticas sociais e mercado de trabalho. São pautas essenciais para a formação dos petianos e dos alunos em geral. $O$ conhecimento adquirido nos debates poderá ser aproveitado pelos bolsistas, discentes, docentes e pessoas da cidade interessadas nos assuntos debatidos.

Outra atividade elaborada pela equipe PET-RTV foi o "Curso PET de Produção Cenográfica e Cenografia Digital”, atividade destinada aos integrantes do grupo PET Rádio e TV da Faculdade de Arquitetura, Artes e Comunicação (FAAC-Unesp), à comunidade acadêmica e aos demais interessados. $O$ curso realizado a cada 15 dias teve a finalidade de apresentar aos participantes conhecimentos teóricos, técnicos e práticas profissionais necessárias para a produção de cenários físicos e virtuais para a TV digital e outros meios audiovisuais.

As aulas foram estruturadas em encontros quinzenais para estudo dos processos teórico-práticos sobre a produção cenográfica, da concepção de croquis, passando pela produção do desenho técnico até as formas de construção de cenários físicos ou computacionais. A motivação para organizar a atividade foi a urgência de qualificação de estudantes de graduação e de pós-graduação, para lidar com as especificidades da linguagem e da técnica intrínsecas à produção audiovisual para TV e outras formas de criação de gêneros e formatos audiovisuais para meios e suporte digitais. Outra finalidade, foi de inserir a temática nos cursos de graduação em comunicação e em áreas afins, dos Cursos da FAAC-Unesp, cujos currículos ainda se concentram em produção cenográfica para meios audiovisuais analógicos. 
A TVD apresenta imagens com melhor definição, recursos de interatividade e recepção em dispositivos portáteis, elementos que impõe novos desafios para a produção cenográfica televisual. Os alunos participantes do curso estarão aptos a transferir o conhecimento adquirido no minicurso para outras pessoas que estejam interessadas no assunto, por meio de atividades destinadas para a graduação, ou de projetos individuais extra-acadêmicos, inserindo a discussão das técnicas abordadas pela ministrante. No estudo prático houve a confecção de um cenário modular, mutável e móvel, híbrido entre físico e digital, que será utilizado primeiramente pelos Núcleos Audiovisual do Grupo PET e Projeto "Alfabetização audiovisual educativa".

\section{REFERÊNCIAS}

DESSEN, M. A. O Programa Especial de Treinamento - PET: evolução e perspectivas futuras. Didática, v. 30, p.27-43, 1995

DURHAN, Eunice R. A reforma da Universidade. Revista da Universidade de São Paulo, São Paulo, n. 4, p. 10-41, março. 1987.

GOMES, F.J.; CARVALHO, H.H.B. Educação em controle e automação em ambiente adverso: estudo de caso de uma experiência tutorial. Anais: XXXIV - Congresso Brasileiro de Ensino de Engenharia. Passo Fundo: UPF, 2006.

MARTIN, M. G. M. B.; O Programa de Educação Tutorial - PET: formação ampla a graduação, UFPR. 96 p. Tese (Mestrado) Programa de Mestrado em Educação, Universidade Federal do Paraná, Curitiba, 2005

MÜLLER, Angélica, Qualidade no ensino superior: a luta em defesa do programa especial de treinamento.1. ed. Rio de Janeiro: Ed. Garamond, 2003.172 p, il.

Programa de Educação Tutorial. Manual de orientações básicas - PET/2002. Disponível em: Seção Documentos. Disponível em: <www.pet.dfi.uem.br/petreage/index.html> Acesso em set. 2012.

SANTOS FILHO, D.J. dos; MOSCATO, L.A.; MIYAGI, P.E.; COZMAN, F.G.; KANO, C.H. Educação tutorial: Uma proposta de formação diferenciada em engenharia. Anais: XVIII - Encontro Anual da Associação Brasil-Japão de Pesquisadores. São Paulo: USP, 2009.

RECEBIDO EM: 15/10/12

ACEITO PARA PUBLICAÇÃO: 09/11/12 


\section{Antonio Francisco Magnoni}

Jornalista e professor de Jornalismo Radiofônico do Departamento de Comunicação Social da Faculdade de Arquitetura, Artes e Comunicação do campus de Bauru da Universidade Estadual Paulista "Julio de Mesquita Filho" (Unesp). Tem experiência profissional e acadêmica nas áreas de: políticas e gestão de comunicação; comunicação educativa para meios digitais; jornalismo radiofônico; meios sonoros e audiovisuais; web-rádio; jornalismo convergente; ensino, pesquisa e extensão via internet. Tutor do Grupo PET do curso de Rádio e Televisão da FAAC/Unesp.

\section{Giovani Vieira Miranda}

Graduando do curso de Comunicação Social-Jornalismo na Faculdade de Arquitetura, Artes e Comunicação (FAAC) da Universidade Estadual Paulista "Julio de Mesquita Filho", campus de Bauru. Coordenador Discente do Grupo PET do curso de Rádio e TV e bolsista de Iniciação Científica pela fundação de Amparo à Pesquisa do Estado de São Paulo (Fapesp) com o projeto "Perspectivas e percepções do novo rádio: um estudo de recepção do conteúdo radiofônico atual entre os ouvintes na Geração Y" 